\title{
PSYCHOGENIC STATUS EPILEPTICUS
}

Six (21\%) of 29 children admitted to the Columbus Children's Hospital, OH, in a 6-month prospective period, with a diagnosis of convulsive status epilepticus proved to have psychogenic status epilepticus and comorbid affective and anxiety disorders. All "seizures" were resistant to antiepileptic drug therapy, and video EEG monitoring documented the nonepileptic nature of the attacks. Ages ranged from 9 to 15 years. All had normal intelligence, and most had a family or personal history of epilepsy. Psycho-therapeutic and -pharmacological interventions were successful, despite some family denial and resistance, the disorder resolving in 1 year or less. (Pakalnis A, Paolicchi J, Gilles E. Psychogenic status epilepticus in children: psychiatric and other risk factors. Neurology February 2000;54:969-970). (Reprints: Dr Ann Pakalnis, Section of Neurology, Children's Hospital, 700 Children's Drive, Columbus, $\mathrm{OH} 43205$ ).

COMMENT. Risk factors for nonepileptic status epilepticus in these patients included comorbid anxiety or depression, a personal or family history of epilepsy, and stressful environmental factors (parents' divorce, move, or loss of employment, school problems, and death of a grandparent). Goals of treatment include avoidance of iatrogenic complications from aggressive misdirected antiepileptic therapy, recognition and therapy of comorbid psychiatric disorder, removal of guilt feelings by counseling, and improvement of family support systems.

Negative emotions in children with newly diagnosed epilepsy were investigated at the Wilhelmina Children's Hospital, Utrecht, The Netherlands. (Oostrom KJ, Schouten A, Olthof T et al. Epilepsia March 2000;41:326-331). Attributions of shame and guilt were evaluated in non-illness, illness, and epilepsy related situations in 36 children with epilepsy, aged 7-15 years, and 35 healthy control children. The test was given twice: soon after diagnosis, and 3 months later. Children with epilepsy and controls did not differ in their way of attributing shame and guilt, but both attributed more shame to incompetence due to epilepsy than that due to other illnesses. Epilepsy was viewed as different from other diseases, suggesting that a stigma is still attached to the diagnosis.

\section{NEUROCUTANEOUS SYNDROMES}

\section{BRAIN VOLUME AND INTELLIGENCE IN NEUROFIBROMATOSIS 1}

Brain morphology and neuropsychological functioning were examined in 52 children and adolescents with neurofibromatosis type 1 (NF-1), and findings compared with 19 controls, at the University of Texas MD Anderson Cancer Center, Houston, TX. Total brain volume and especially gray matter, by quatitative MRI, was significantly greater for NF-1 subjects than controls, and the difference was more pronounced in younger subjects. The volume of gray matter in NF-1 patients was correlated with the degree of learning disability and a greater discrepancy between academic potential (IQ) and performance (academic achievement). A significantly greater regional corpus callosum size in NF-1 subjects was associated with diminished performance in tests of academic achievement and visuo-spatial and motor skills. (Moore BD III, Slopis JM, Jackson EF et al. Brain volume in children with neurofibromatosis type 1. Relation to neuropsychological status. Neurology February 2000;54:914-920). (Reprints: Dr Bartlett D Moore III, Division of Pediatrics (Box 87), University of Texas MD Anderson Cancer Center, 1515 Holcombe Blvd, Houston, TX 77030). 